\title{
Green synthesis of silver nanoparticles mediated by Pulicaria glutinosa extract
}

This article was published in the following Dove Press journal:

International Journal of Nanomedicine

16 April 2013

Number of times this article has been viewed

\author{
Mujeeb Khan' \\ Merajuddin Khan' \\ Syed Farooq Adil' \\ Muhammad Nawaz Tahir ${ }^{2}$ \\ Wolfgang Tremel ${ }^{2}$ \\ Hamad Z Alkhathlan' \\ Abdulrahman Al-Warthan' \\ Mohammed Rafiq \\ H Siddiqui' \\ 'Department of Chemistry, College of \\ Science, King Saud University, Riyadh, \\ Kingdom of Saudi Arabia; ${ }^{2}$ Institute of \\ Inorganic and Analytical Chemistry, \\ Johannes Gutenberg-University of \\ Mainz, Mainz, Germany
}

Correspondence: Mohammed

Rafiq H Siddiqui

Department of Chemistry, College of

Science, King Saud University, PO 2455,

Riyadh I I45I, Kingdom of Saudi Arabia

Tel +966 | 4676082

Fax +966 | 4676082

Email rafiqs@ksu.edu.sa

\begin{abstract}
The green synthesis of metallic nanoparticles (NPs) has attracted tremendous attention in recent years because these protocols are low cost and more environmentally friendly than standard methods of synthesis. In this article, we report a simple and eco-friendly method for the synthesis of silver NPs using an aqueous solution of Pulicaria glutinosa plant extract as a bioreductant. The as-prepared silver NPs were characterized using ultraviolet-visible spectroscopy, powder X-ray diffraction, transmission electron microscopy, energy-dispersive $\mathrm{X}$-ray spectroscopy, and Fourier-transform infrared spectroscopy. Moreover, the effects of the concentration of the reductant (plant extract) and precursor solution (silver nitrate), the temperature on the morphology, and the kinetics of reaction were investigated. The results indicate that the size of the silver NPs varied as the plant extract concentration increased. The as-synthesized silver NPs were phase pure and well crystalline with a face-centered cubic structure. Further, Fourier-transform infrared spectroscopy analysis confirmed that the plant extract not only acted as a bioreductant but also functionalized the NPs' surfaces to act as a capping ligand to stabilize them in the solvent. The developed eco-friendly method for the synthesis of NPs could prove a better substitute for the physical and chemical methods currently used to prepare metallic NPs commonly used in cosmetics, foods, and medicines.
\end{abstract}

Keywords: surface plasmon resonance, metallic nanoparticles, eco-friendly, capping ligand

\section{Introduction}

Metallic nanoparticles (NPs) have attracted the attention of the scientific community and technologists due to their ever-emerging, numerous, and fascinating applications in various fields, including biomedical sciences and engineering. ${ }^{1-3}$ For instance, the unique optoelectronic and physicochemical properties of metal NPs have already been successfully exploited for the purpose of drug delivery, ${ }^{4}$ tissue/tumor imaging, ${ }^{5}$ biosensing, ${ }^{6}$ catalysis, ${ }^{7}$ and surface-enhanced Raman scattering-based sensors. ${ }^{8}$ The commonly employed methods for the synthesis of metallic NPs involve toxic chemicals, hazardous conditions, and costly apparatus. In comparison, the green synthesis of metallic NPs involves biocompatible ingredients under physiological conditions of temperature and pressure. Moreover, the biologically active molecules involved in the green synthesis of NPs act as functionalizing ligands, making these NPs more suitable for biomedical applications. ${ }^{9}$ Therefore, the development of such protocols to synthesize nontoxic metal NPs is currently of great interest and there is thus a demand for biosynthetic or green methods for this purpose. ${ }^{10}$

Several methods have been used for the green synthesis of NPs using various biological materials as reducing agents such as microorganisms, marine organisms, micro-fluids, 
and plant extracts. ${ }^{11-14}$ Among the most important bioreductants are plant extracts, which are relatively easy to handle, readily available, low cost, and have been well explored for the green synthesis of other nanomaterials. ${ }^{15-19}$ Various types of metallic NPs have already been synthesized using plant extracts.

Silver (Ag) in the nanoscale form exhibits remarkably unusual physicochemical and biological activities, thus has been widely applied in the health care sector. ${ }^{20,21}$ In particular, the outstanding antimicrobial properties of Ag NPs have led to the development of a wide variety of nanosilver products, including nanosilver-coated wound dressings, contraceptive devices, surgical instruments, and implants. ${ }^{22,23}$ Apart from these antimicrobial activities, Ag NPs are also known to possess antifungal, anti-inflammatory, antiviral, anti-angiogenesis, and antiplatelet properties. ${ }^{24-26}$ Additionally, more recent developments have seen Ag NPs used in room spray, laundry detergent, and wall paint formulations as well as in the textile industry for clothing manufacturing. ${ }^{27-30}$

The fascinating properties of Ag NPs mostly depend on the size and shape of the NPs. It has also been widely reported that less aggregated, small, and spherical-shaped Ag NPs have proven more effective for most applications than Ag NPs with other morphologies. ${ }^{31-33}$ Over the years, several studies have been published regarding the green synthesis of Ag NPs with attention paid to controlling the size and shape of the NPs and using plant extracts as reducing agents. ${ }^{34-36}$ For example, one study examined polydispersed spherical Ag NPs of different sizes ranging from 5 to $100 \mathrm{~nm}$, which were obtained using aqueous coffee and tea leaf extracts, while another study looked at the leaves of different tea species for a similar purpose. ${ }^{37,38}$ Apart from the leaf, extracts of several other parts of various plants have also been tried as bioreductants for the preparation of Ag NPs, including the tuber of Curcuma longa in powdered form, ${ }^{39}$ coir of Cocos nucifera, ${ }^{40}$ root of Morinda citrifolia, ${ }^{41}$ berry of Solanum xanthocarpum, ${ }^{42}$ fruit of Terminalia chebula, ${ }^{43}$ and stem bark of Callicarpa maingayi. ${ }^{44}$ Additionally, in many other cases, various small whole plants have been used to synthesize Ag NPs. ${ }^{45,46}$

In the present study, we used the extract of Pulicaria glutinosa, which was collected from local fields in Saudi Arabia as part of our research on Saudi Arabian plants for the development of products with potential economic value. ${ }^{47,48}$ Pulicaria is a relatively large genus of plants belonging to the tribe Inuleae of the daisy family Compositae. It comprises about 100 species distributed from Europe to North Africa and Asia, particularly around the Mediterranean. ${ }^{49}$ Many plant species of the genus Pulicaria are used in traditional herbal medicines around the world for various purposes such as inflammation, diarrhea, dysentery, back pain, intestinal disorders and menstrual cramps. ${ }^{50}$ Further, several of the organic compounds present in $P$. glutinosa plant extract (which were identified via detailed spectroscopic analysis of the plant extract; data to be published elsewhere) contain a large number of phenolic groups, which are known to play a vital role in the reduction of $\mathrm{Ag}^{+}$ions. ${ }^{51}$

Herein, we report on the green synthesis of Ag NPs via the reduction of $\mathrm{Ag}$ ions using an aqueous extract of P. glutinosa plant (Figure 1). During the study, a detailed
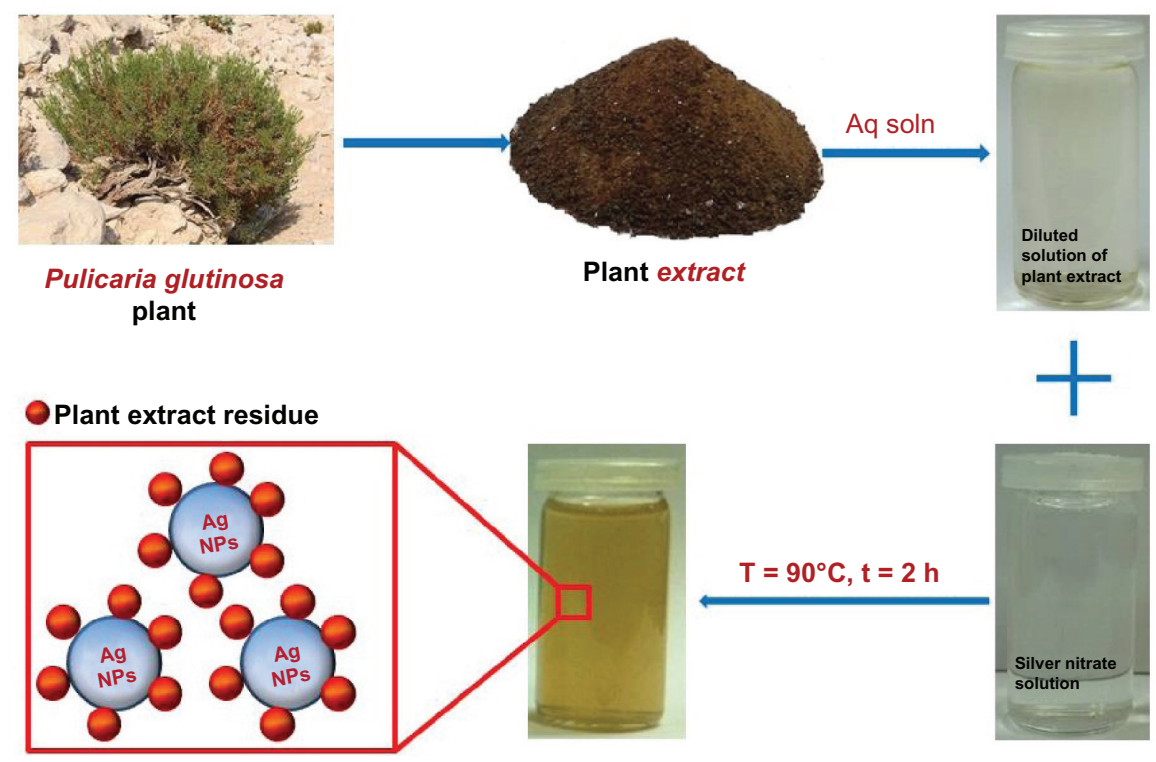

Figure I Schematic illustration of the green synthesis of silver nanoparticles (Ag NPs) using aqueous extract of the Pulicaria glutinosa plant. Abbreviations: Aq soln, aqueous solution; t, time; T, temperature. 
analysis was undertaken of the effects of the concentrations of the reactant (silver nitrate $\left[\mathrm{AgNO}_{3}\right]$ ) and reductant (extract of $P$. glutinosa) as well as the effects of the reaction temperature on the size and morphology of Ag NPs. The as-prepared Ag NPs were characterized using various microscopic and analytical techniques including X-ray powder diffraction (XRD), Fourier-transform infrared spectroscopy (FT-IR), ultraviolet-visible absorption (UV-Vis) spectroscopy, and transmission electron microscopy (TEM).

\section{Materials and methods Materials}

The whole plant of wild growing $P$. glutinosa was collected from the hilly area of Al-Hair in central Saudi Arabia during March 2011. The identity of the plant material was confirmed by a plant taxonomist from the Herbarium Division of the College of Science, King Saud University, Riyadh, Kingdom of Saudi Arabia. A voucher specimen was deposited in our laboratory as well as in the Herbarium Division of King Saud University with the voucher specimen number KSU-21598. $\mathrm{AgNO}_{3}$ (99.8\%) was purchased from SigmaAldrich (St Louis, MO, USA).

\section{Preparation of plant extract}

The aerial parts of freshly collected $P$. glutinosa plants were chopped into small pieces. The resultant pieces (245.0 g) were soaked in deionized water $(2500 \mathrm{~mL})$ and refluxed for 3 hours. The aqueous solution obtained after reflux was filtered and dried at $50^{\circ} \mathrm{C}$ under reduced pressure in a rotary evaporator to give a powder of dark brownish color (17.20 g). A small amount of the powdery extract $(0.1 \mathrm{~g} / \mathrm{mL})$ was used for the synthesis of Ag NPs.

\section{Synthesis of Ag NPs}

The reaction mixture was prepared by adding $1 \mathrm{~mL}$ of the plant extract to $99 \mathrm{~mL}$ of $1 \mathrm{mM} \mathrm{AgNO}(169.87 \mathrm{mg})$ solution in a $250 \mathrm{~mL}$ round-bottom flask, which was mounted with a cooling condenser and magnetic stir bar. The mixture was allowed to stir for 2 hours at $90^{\circ} \mathrm{C}$ (immediate color change was observed from light yellow to dark brown, and thereafter no further color change was observed even after 2 hours). After 2 hours, the mixture was allowed to cool down before being centrifuged. The centrifugation was performed at room temperature and a speed of $9000 \mathrm{rpm}$. After washing three times with distilled water, a black powder was obtained that was dried overnight in an oven at $80^{\circ} \mathrm{C}$.

To elucidate the effects of the plant extract, various experiments were carried out by mixing 1.0, 2.5, 5.0, 7.5, and $10 \mathrm{~mL}$ aqueous solutions of plant extract and $1 \mathrm{mmol}$ of $\mathrm{AgNO}_{3}(169.87 \mathrm{mg})$ in respective amount of Milli-Q water to make a total volume of $100 \mathrm{~mL}$. Similarly, for $\mathrm{AgNO}_{3}$, the quantity of plant extract was kept constant at $7.5 \mathrm{~mL}$, but the amount of $\mathrm{AgNO}_{3}$ was varied in each experiment (1.0, 2.5, and $5.5 \mathrm{mmol})$. All experiments were carried out at $90^{\circ} \mathrm{C}$, except those that were carried out at room temperature (RT) to study the effect of temperature on the synthesis of NPs.

\section{Characterization of NPs UV-Vis spectroscopy}

A Lambda 35 UV-Vis spectrophotometer (PerkinElmer, Waltham, MA, USA) was used to conduct optical measurements. The analysis was performed in quartz cuvettes, using distilled water as a reference solvent. The samples for the ultraviolet (UV) measurements of crude mixture were prepared by diluting $1 \mathrm{~mL}$ of mixture (collected at the end of reaction) in $9 \mathrm{~mL}$ of water and sonicating for 15 minutes. Pure Ag NP samples for UV-Vis analysis were prepared by diluting $2 \mathrm{~mL}$ of pure $\mathrm{Ag}$ NP stock solution in $8 \mathrm{~mL}$ of water. The stock solution was prepared by dispersing $5 \mathrm{mg}$ of $\mathrm{Ag}$ NPs in $5 \mathrm{~mL}$ of water and sonicating for 1 hour.

XRD

XRD patterns were obtained on an Ultima IV X-ray powder diffractometer (Rigaku, Tokyo, Japan) using $\mathrm{Cu} \mathrm{K} \alpha$ radiation $(\lambda=1.5418 \AA)$.

\section{TEM and EDX}

TEM and EDX was performed on a JEM 1101 transmission electron microscope (JEOL, Tokyo, Japan). The samples for TEM were prepared by placing a drop of primary sample on a copper grid, which was then dried for 6 hours at $80^{\circ} \mathrm{C}$ in an oven.

\section{FT-IR spectroscopy}

FT-IR spectra were obtained on a PerkinElmer 1000 FT-IR spectrometer. To remove any free biomass residue or unbound extract on the surfaces of the NPs, the Ag NPs were repeatedly washed with distilled water; subsequently the product was centrifuged at $9000 \mathrm{rpm}$ for $30 \mathrm{~min}$ and dried. The purified Ag NPs were mixed with $\mathrm{KBr}$ powder and pressed into a pellet for measurement. Background correction was made using a reference blank $\mathrm{KBr}$ pellet.

\section{Results and discussion}

P. glutinosa plant extract was used for the synthesis of $\mathrm{Ag}$ NPs under facile conditions. It was observed that on the 
addition of plant extract into the aqueous solution of $\mathrm{AgNO}_{3}$, the color of the solution gradually changed from light yellow to dark brown, indicating the formation of Ag NPs (Figure 2B). Under a similar set of conditions, no change in the color of $\mathrm{AgNO}_{3}$ solution was observed even after 72 hours (Figure 2A). This color change occurred relatively faster at $90^{\circ} \mathrm{C}$ (in less than 2 hours) than at RT. This observation is in accordance with previously reported study by Mohan Kumar et al, in which the speed of NP formation has been found to increase as the temperature and incubation period increase. ${ }^{46}$ The formation of the as-prepared Ag NPs was initially monitored by UV-Vis analysis. Typically, Ag NPs exhibit absorption under a visible range of $380-450 \mathrm{~nm}$, depending on the shape and size of the NPs. ${ }^{51,52}$

\section{UV-Vis spectroscopic analysis}

UV-Vis absorption spectroscopy is an important technique to monitor the formation and stability of metal NPs in aqueous solution. The absorption spectrum of metal NPs is sensitive to several factors, including particle size, shape, and particle-particle interaction (agglomeration) with the medium. ${ }^{52}$ Therefore, the aqueous bioreduction of $\mathrm{Ag}^{+}$ions can be effectively monitored by a UV-Vis spectrophotometer. Figure 3 shows the absorption spectra of Ag NPs prepared at different temperatures. The results reveal that the synthesis of Ag NPs using $P$. glutinosa is significantly faster at elevated temperature $\left(90^{\circ} \mathrm{C}\right)$ than at $\mathrm{RT}$.

Figure 4 displays the UV-Vis spectra of Ag NPs prepared at RT and $90^{\circ} \mathrm{C}$, which were recorded at regular intervals of time. At $90^{\circ} \mathrm{C}$, it was observed that the nucleation started very quickly and the formation of Ag NPs was very fast until around 60 minutes had passed, which is clearly reflected by the gradual increase in the intensity of the surface plasmon

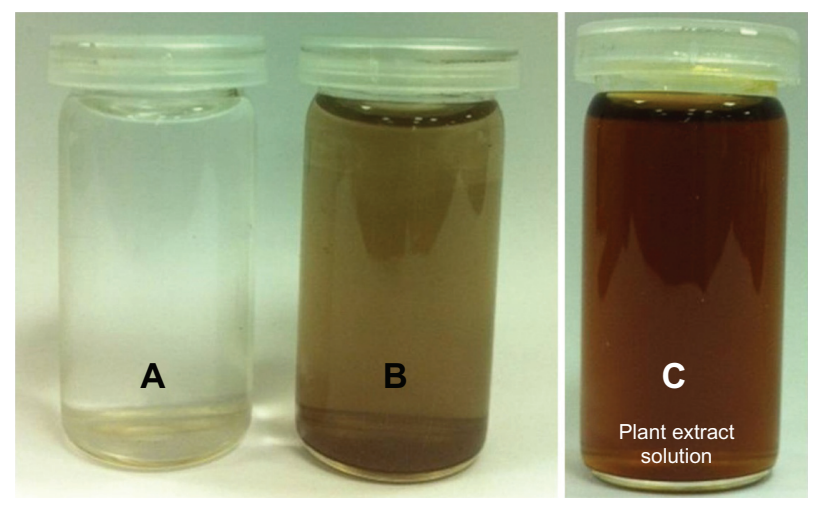

Figure 2 Digital photograph of the aqueous solutions of $(\mathbf{A})$ silver nitrate $\left(\mathrm{AgNO}_{3}\right)$ without addition of the plant extract, $(\mathbf{B}) \mathrm{AgNO}_{3}$ with the addition of the plant extract, and photograph of $(\mathbf{C})$ the pure plant extract at a concentration of $0.1 \mathrm{~g} / \mathrm{mL}$. Images (A and $\mathbf{B})$ were recorded after 72 hours. resonance (SPR) bands (Figure 4A). Thereafter, the process slowed down and, after 80 minutes had passed, no further change in the SPR band was observed, which is an indication of the completion of reaction. However, at RT, the nucleation process was very slow from the beginning and the reaction took almost 20 hours to complete (Figure 4B). At both temperatures, the SPR band shapes remain similar. This trend can be attributed to the gradual and slow nucleation of the NPs, due to the slower rate of reaction at lower temperatures (Figure 4B). Further, the lower intensity of the SPR band of Ag NPs formed at RT in Figure 3A indicates a smaller yield of NPs when compared to the yield of Ag NPs formed at $90^{\circ} \mathrm{C}$.

Additionally, the effects of the plant extract concentration on the synthesis of Ag NPs were also evaluated using UV-Vis spectroscopy. Figure 5A shows the absorption spectra of Ag NPs prepared using different concentrations of plant extract. All experiments were carried out by varying the concentration of $P$. glutinosa extract, keeping other conditions constant

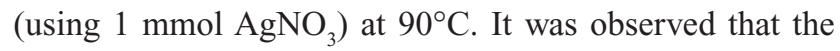
concentration of the plant extract exerted a significant effect on the size and size distribution of the NPs (Figure 5A). Generally, a broad peak at a higher wavelength indicates an increase in particle size, whereas a narrow line at a shorter wavelength represents smaller particle size. ${ }^{52}$ In this case, as the concentration of the plant extract was varied from 1 to $5 \mathrm{~mL}$, it was found that the SPR bands were blue shifted from $455 \mathrm{~nm}$ to $422 \mathrm{~nm}$, with a simultaneous increase in the absorption coefficient. In contrast, with further increases in concentration, the bands became sharper and shifted to longer wavelengths - that is, from 422 to $459 \mathrm{~nm}$.

The initial shift toward the shorter wavelength with increasing extract concentration is characteristic of a decrease in particle size, which could be the result of an increase in nucleation due to the enhanced reduction process (like the increased nucleation that occurs in the polyol solution synthesis of metallic NPs). In contrast, further increasing the extract concentration (which also increased the reduction process) resulted in further growth (Ostwald ripening) of the NPs, which gave rise to a red shift of the SPR band (toward a longer wavelength). The sharpness of the absorption band with increasing plant extract concentration was due to the better stabilization of the NPs' surfaces because the plant extract also acts as surface functionalizing ligand. This is also reflected by the color change of the diluted pure Ag NP solution from light to dark brown as the plant extract concentration increased. A comparative study was also carried out to investigate the effects of $\mathrm{AgNO}_{3}$ concentration (1.0, 

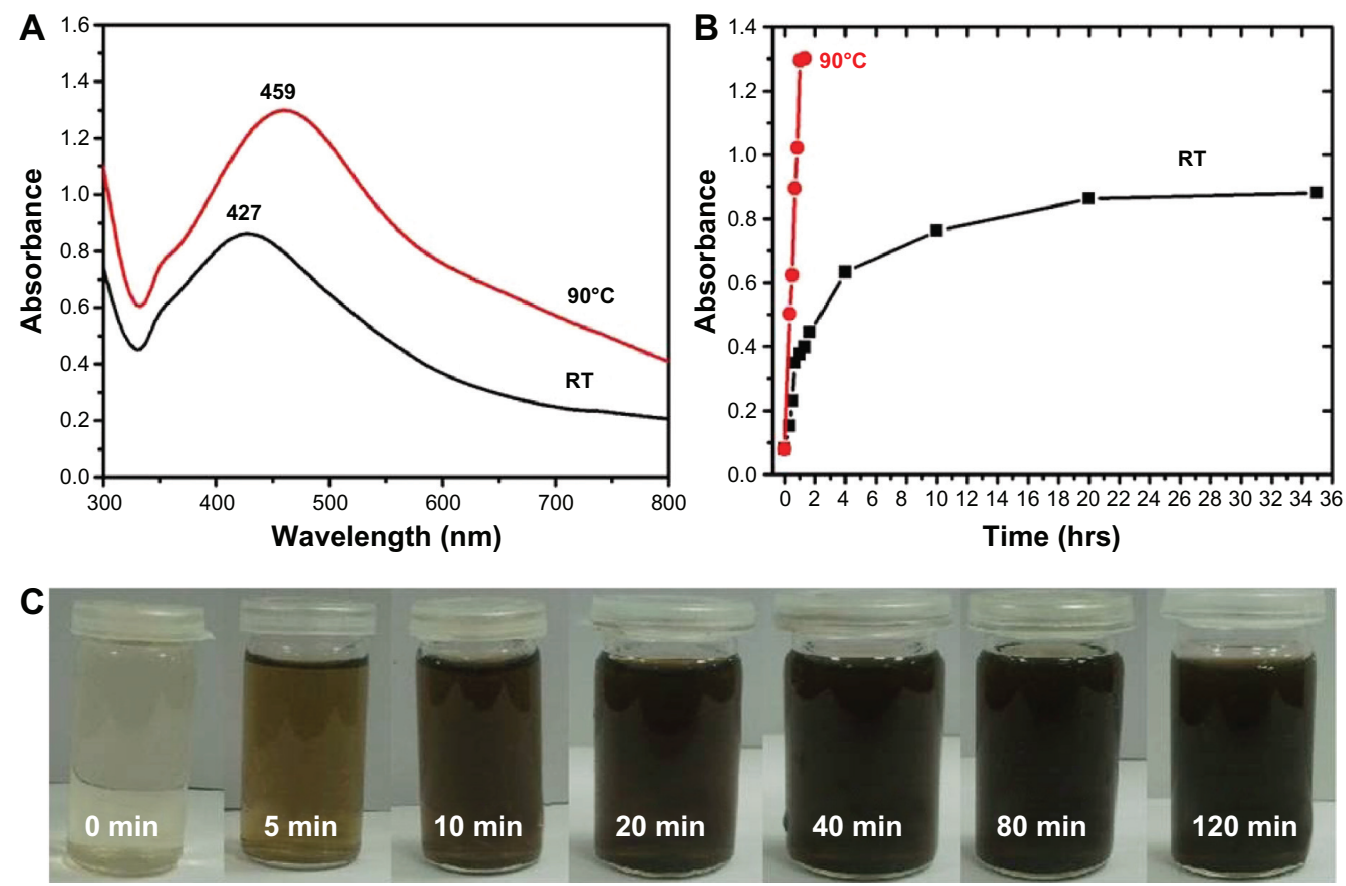

Figure 3 Ultraviolet-visible (UV-Vis) absorption spectra (A and B) and visual appearance of the silver nanoparticle (Ag NP) solution (C). (A) Comparison between UV-Vis spectra of $\mathrm{Ag} N \mathrm{~N}$ s prepared at room temperature (RT) and at $90^{\circ} \mathrm{C}$. (B) Plot of the absorption wavelength of $\mathrm{Ag} N \mathrm{Ns}$ at different temperatures. (C) Color change of the solution at $90^{\circ} \mathrm{C}$. The samples shown in $(\mathbf{C})$ were obtained during the reaction and photographs recorded before final workup.

2.5, and $5.0 \mathrm{mmol}$, respectively) on preparation of Ag NPs. Figure 5B shows the UV-Vis spectra of Ag NPs obtained at various aqueous $\mathrm{AgNO}_{3}$ concentrations while the plant extract concentration was kept constant $(7.5 \mathrm{~mL})$ at $90^{\circ} \mathrm{C}$ for 2 hours. It was observed that, as the concentration of $\mathrm{AgNO}_{3}$ increased, the SPR band shifted from $447 \mathrm{~nm}(1 \mathrm{mmol})$ to $455 \mathrm{~nm}$ ( $5 \mathrm{mmol})$, indicating a slight increase in particle size.

Figure 5C is a digital photograph of the diluted solutions of pure Ag NPs prepared with different plant extract concentrations. The darker pure Ag NPs solution prepared with $10 \mathrm{~mL}$ of extract indicates the presence of plant extract residue in higher amounts as a capping agent to the Ag NPs. Therefore, at a higher concentration of plant extract, less aggregated but larger NPs were formed. It was also observed that, when the concentration of the plant extract was increased, the intensities of the SPR bands also increased, which indicates that there is a higher yield of Ag NPs at higher concentrations (Figure 5A). ${ }^{40}$
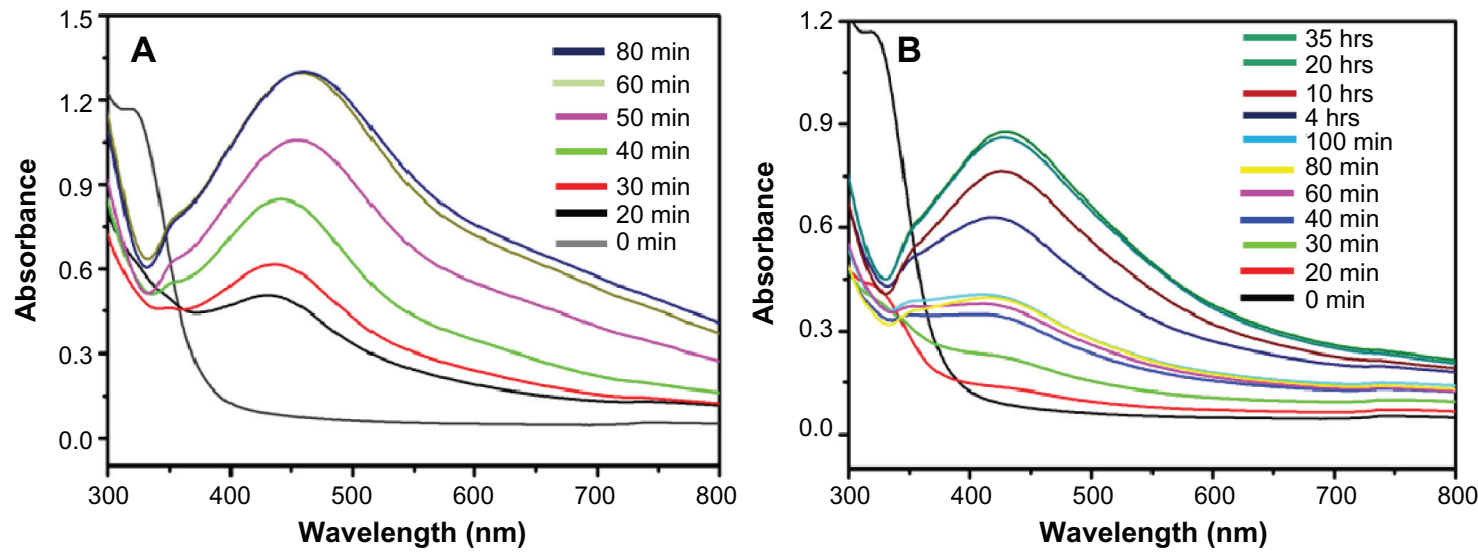

Figure 4 Ultraviolet-visible absorption spectra of silver nanoparticles (Ag NPs) prepared at (A) $90^{\circ} \mathrm{C}$ using I mmol of silver nitrate and $7.5 \mathrm{~mL}$ of plant extract and (B) at room temperature using I mmol of silver nitrate and $7.5 \mathrm{~mL}$ of plant extract.

Note: All spectra were obtained by taking $\mathrm{I} \mathrm{mL}$ of the sample at regular intervals and further diluting it with $9 \mathrm{~mL}$ of water then sonicating for $\mathrm{I} 5 \mathrm{minutes}$. 

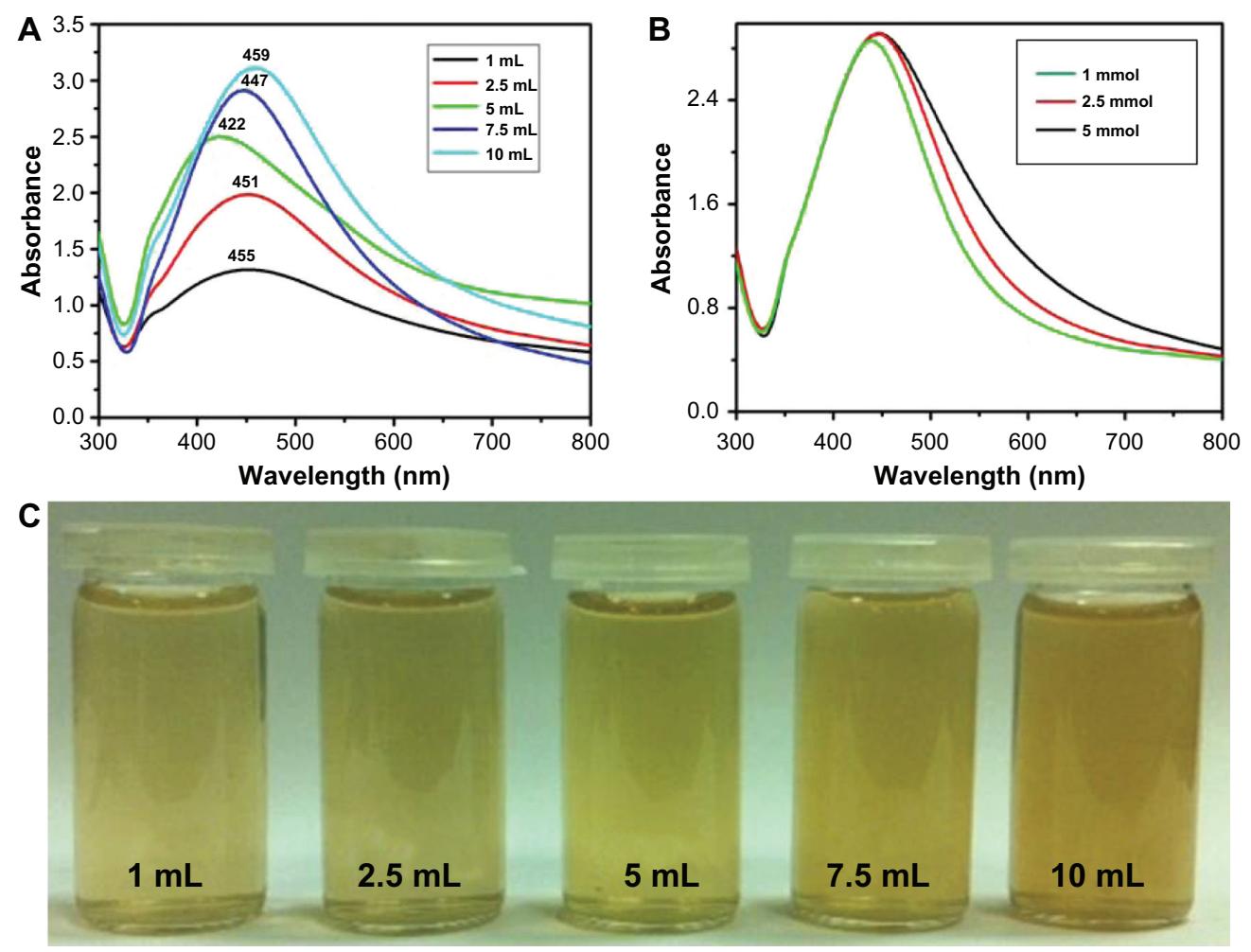

Figure 5 Ultraviolet-visible absorption spectra of silver nanoparticles (Ag NPs) prepared at $90^{\circ} \mathrm{C}$ for 2 hours using (A) various concentrations of plant extract and keeping the amount of silver nitrate $\left(\mathrm{AgNO}_{3}\right)$ constant at I mmol and (B) various concentrations of $\mathrm{AgNO}_{3}$ and keeping the amount of plant extract constant at $7.5 \mathrm{~mL}$. (C) The diluted solutions of pure Ag NPs (obtained after final workup).

Note: All spectra were measured using same solution concentrations.

\section{XRD}

The crystalline nature of the green synthesized Ag NPs using $P$. glutinosa was confirmed by XRD pattern analysis. The XRD pattern in Figure 6 indicates the face-centered cubic structure of the Ag NPs. There are five distinct reflections in

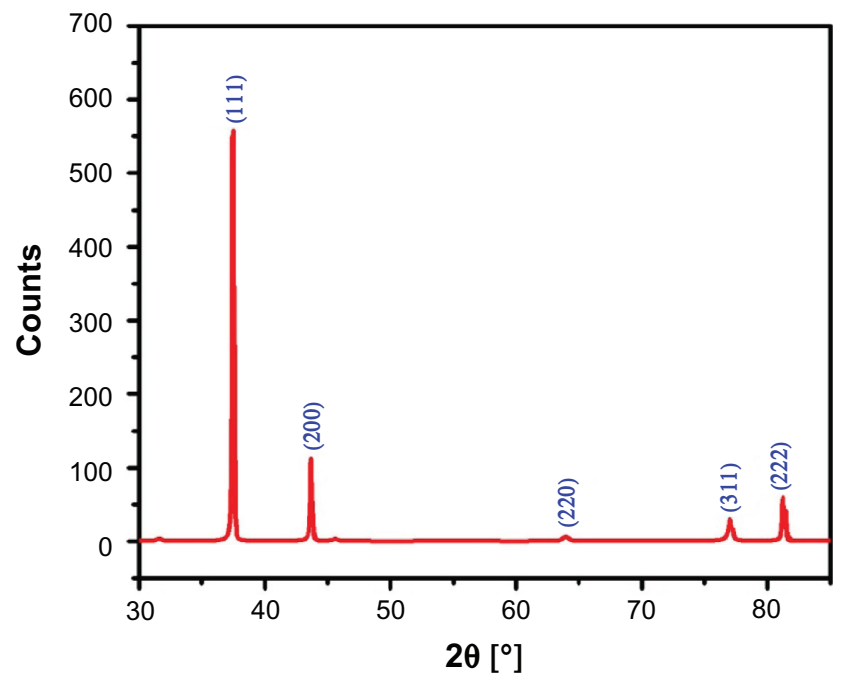

Figure 6 X-ray powder diffraction pattern of the green synthesized silver nanoparticles. the diffractogram at $37.50^{\circ}(111), 44.13^{\circ}(200), 63.91^{\circ}(220)$, $76.89^{\circ}(311)$, and $81.13^{\circ}(222)$. The intense reflection at 111 , in comparison to the other four, may indicate the growth direction of the nanocrystals..$^{53}$ On the basis of the half-width $\left(^{\wedge}\right)$ of the 111 reflection in the powder pattern, the average grain size, $L$ - determined by broadening of the 111 reflection by the Scherer formula - is approximately $42 \mathrm{~nm}$. The absence of any additional reflections other than the reflections belonging to the Ag lattice clearly suggests that the green synthesized Ag NP lattice was unaffected by other molecules in the plant extract.

\section{TEM and energy-dispersive X-ray spectroscopy (EDX) analysis}

The morphology and size of the green synthesized Ag NPs were studied by TEM. Figure 7A shows the as-synthesized NPs. Figure 7B and C clearly show the spherical morphology of the NPs, with a size range of 40-60 nm (Figure 7D), in which few NPs were agglomerated. The agglomeration of NPs decreased as the plant extract concentration was increased (Figure 7C), which is also evidenced by the UVVis spectroscopy results. Further, the elemental composition 

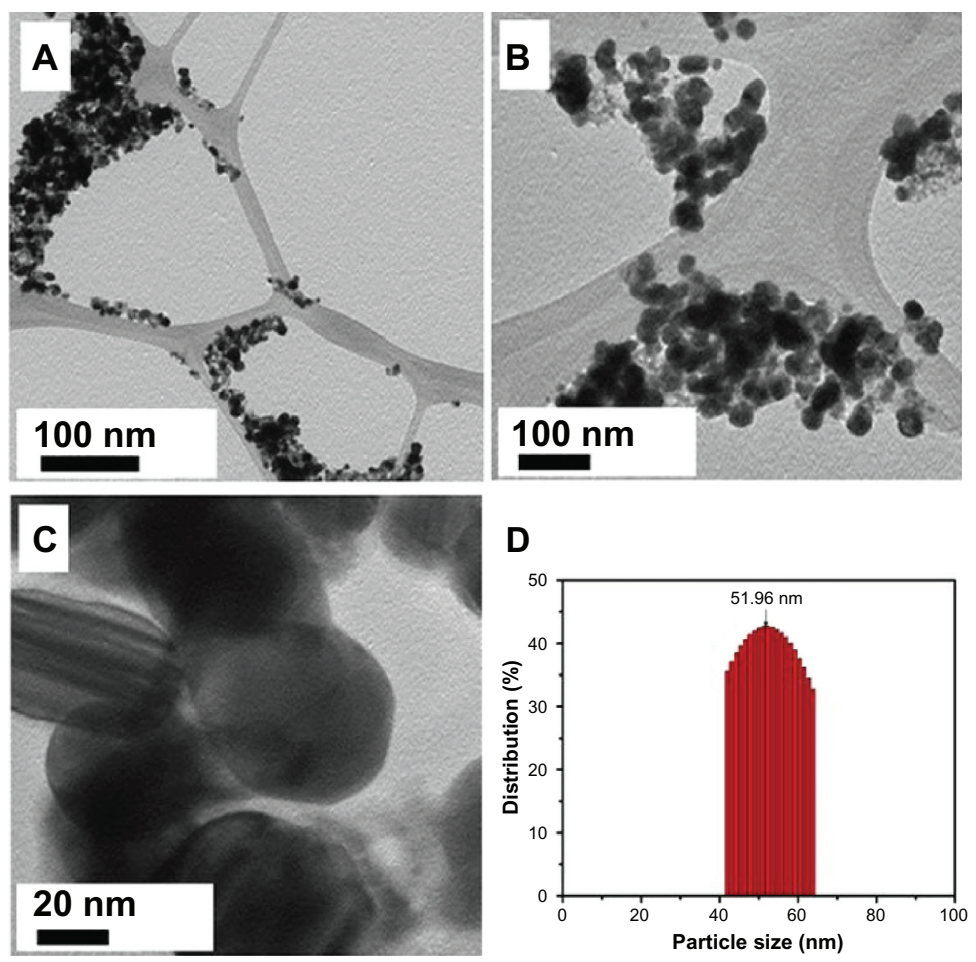

Figure $7(\mathbf{A}-\mathbf{C})$ Transmission electron microscope images of the green synthesized silver nanoparticles (Ag NPsat different scales. (D) Overview of the size range and distribution of the Ag NPs.

Note: With increasing concentration, less agglomeration was observed.

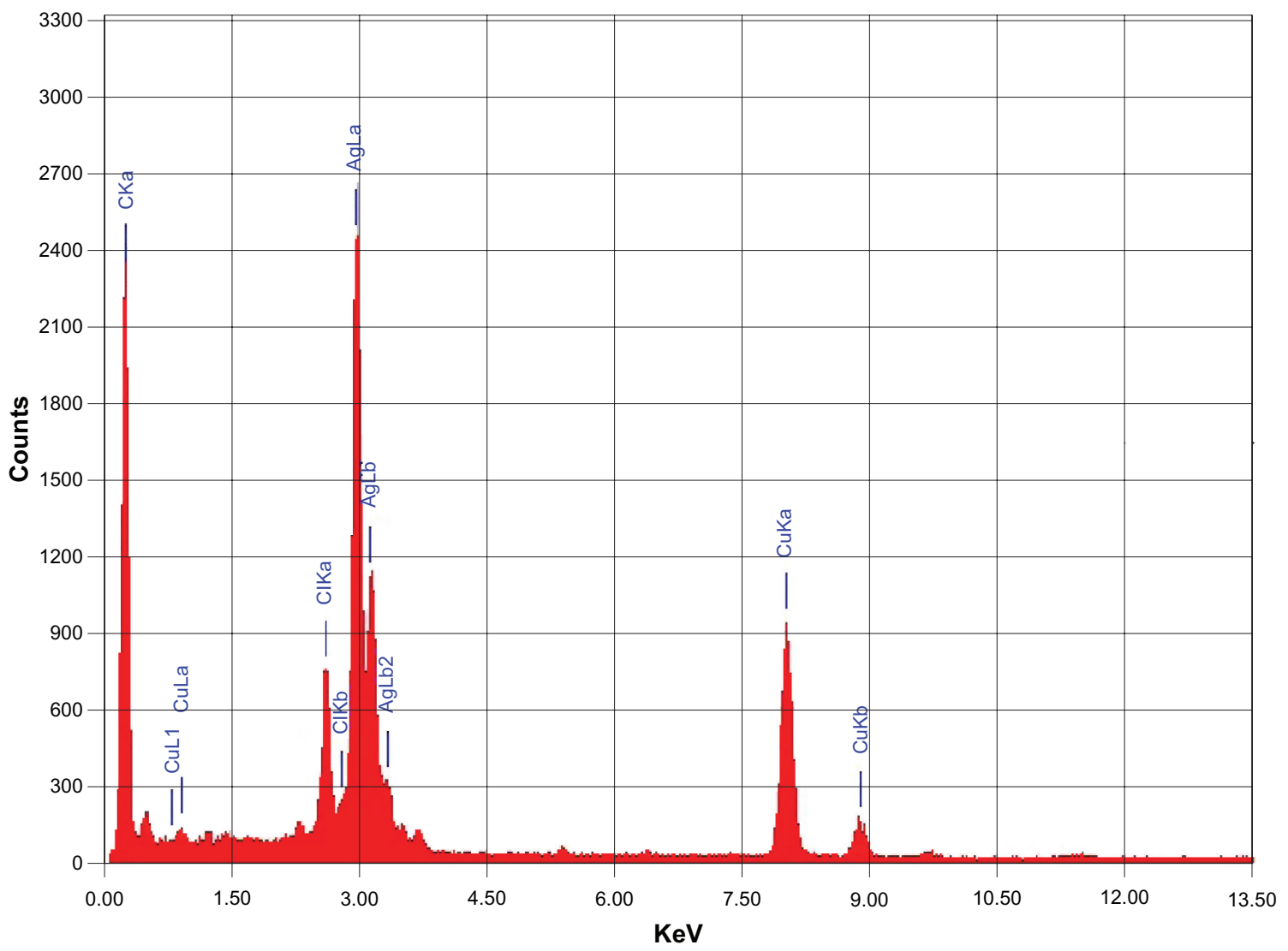

Figure 8 Energy-dispersive X-ray spectrum of green synthesized silver nanoparticles. 
of the green synthesized sample was also determined by EDX. The EDX spectrum, shown in Figure 8, reveals the clear elemental composition profile of the green synthesized Ag NPs. The intense signal at $3 \mathrm{keV}$ strongly suggests that Ag was the major element, which has an optical absorption in this range due to the SPR. ${ }^{36}$ Notably, the other signals in the range of $0.0-0.5 \mathrm{keV}$ - one of which is very intense represent the typical absorption of carbon and oxygen and thus indicates the presence of the plant extract (as a capping ligand) on the surfaces of the NPs.

\section{FT-IR analysis}

The dual role of the plant extract as a bioreductant and capping agent was confirmed by FT-IR analysis of the asprepared Ag NPs. The sample for the infrared analysis was carefully prepared to exclude any possibility of the presence of any unbound plant extract residue. For this purpose, the asprepared Ag NPs after final workup were dispersed again in distilled water via 30 minutes of sonication, and subsequently centrifuged at a speed of $9000 \mathrm{rpm}$ for 30 minutes, and this process was repeated twice to isolate the pure Ag NPs and exclude the presence any unbound ligand. Figure 9 shows the FT-IR spectra of $P$. glutinosa pure plant extract and purified Ag NPs obtained after the bioreduction.

The similarities between the spectra A and B in Figure 9, with some marginal shifts in peak position, clearly indicate the presence of residual plant extract in the sample as a capping agent to the Ag NPs. Detailed analysis of the plant extract spectra strongly suggested the presence of

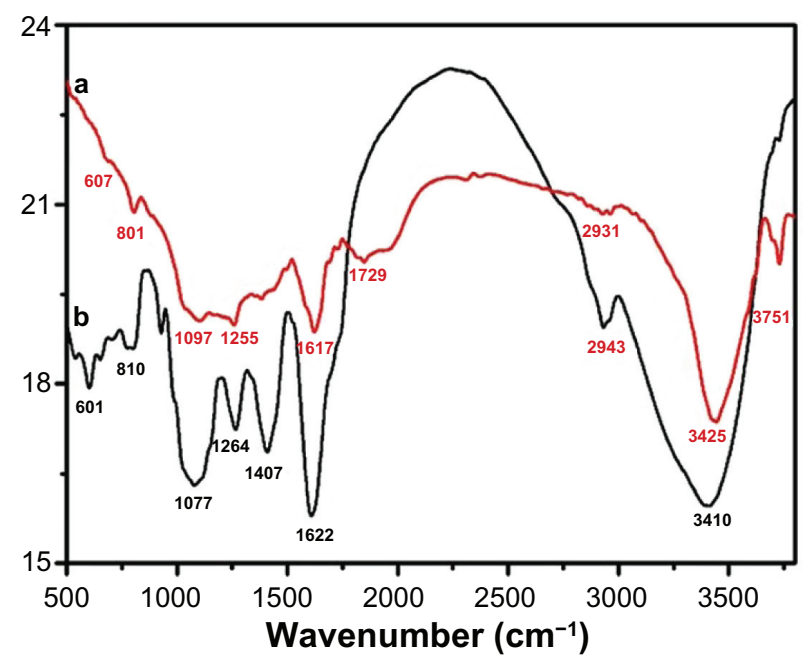

Figure 9 Fourier-transform infrared spectra of pure green synthesized silver nanoparticles (Ag NPs) (line a) and Pulicaria glutinosa plant extract (line b).

Note: The similarities between the spectra strongly suggest the presence of plant extract residue in the Ag NPs as a capping or stabilizing agent. flavonoids and polyphenols, apart from other phytochemicals, which were mainly responsible for the formation of the Ag NPs by reducing the $\mathrm{AgNO}_{3}$. The spectrum of the plant extract shows the absorption peaks at 3746 and $3410 \mathrm{~cm}^{-1}$ corresponding to the hydrogen-bonded hydroxyl $(\mathrm{OH})$ and the peak at $2943 \mathrm{~cm}^{-1}$ indicates the presence of $\mathrm{C}-\mathrm{H}$. The absorption peaks situated around 1753, 1622, and $1407 \mathrm{~cm}^{-1}$ are the characteristic peaks for the $\mathrm{C}-\mathrm{H}$, $\mathrm{C}-\mathrm{C}$, and $\mathrm{C}-\mathrm{O}$ stretching, respectively, of the aromatics. The bands at 1264 and $1077 \mathrm{~cm}^{-1}$ indicate the presence of C-O stretching of alcohols, carboxylic acids, and ester and ether groups. Notably, the absorption band at 1974 and $512 \mathrm{~cm}^{-1}$ in the Ag NP spectrum, in addition to peaks present in the plant extract spectrum, represents the Ag NPs' banding with oxygen from the hydroxyl groups in $P$. glutinosa compounds. ${ }^{39}$ Further, the absorption peak centered at $1729 \mathrm{~cm}^{-1}$ points toward the formation of a new $\mathrm{C}=\mathrm{O}$ group that is either a aldehyde, ketone, or $\mathrm{COOH}$. This strongly suggests that the reduction of Ag was carried out by some hydroxyl groups that get oxidized at the expense of $\mathrm{Ag}$ because $\mathrm{Ag}$ is reduced. ${ }^{54}$

\section{Conclusion}

Herein, a green approach to the synthesis of Ag NPs using P. glutinosa plant extract has been reported. Applying this method, highly crystalline, spherical-shaped Ag NPs were prepared at ambient conditions without using any harmful reducing or capping agents. The concentration of plant material played a critical role in the size and dispersion of the NPs. Although reduction occurred when the plant extract concentration was low, the NPs prepared using a high concentration of plant extract were less aggregated, indicating that the plant extract acted as a capping ligand, and this was confirmed by FT-IR spectroscopy. Studies on the effect of temperature on the preparation of the NPs showed that the reaction proceeded much faster at an elevated temperature than at RT. Moreover, the size and yield of NPs increased when they were synthesized at $90^{\circ} \mathrm{C}$ compared with when they were synthesized at RT.

The protocol presented here for the synthesis of Ag NPs can be extended to other metal NPs due to the fact that P. glutinosa plant extract is highly oxidized in nature and is very likely to be able to reduce metals under physiological conditions. Moreover, its abundancy and low cost also make P. glutinosa plant extract potentially attractive for the upscaling of metallic nanomaterials to explore various catalytic applications. 


\section{Acknowledgments}

This project was supported by King Saud University, Deanship of Scientific Research, College of Science,

Research Center.

\section{Disclosure}

The authors declare no conflicts of interest in this work.

\section{References}

1. Arvizo RR, Bhattacharyya S, Kudgus RA, Giri K, Bhattacharya R, Mukherjee P. Intrinsic therapeutic applications of noble metal nanoparticles: past, present and future. Chem Soc Rev. 2012;41(7):2943-2970.

2. Dykman L, Khlebtsov N. Gold nanoparticles in biomedical applications: recent advances and perspectives. Chem Soc Rev. 2012. 41(6):2256-2282.

3. Otsuka H, NagasakiY, Kataoka K. PEGylated nanoparticles for biological and pharmaceutical applications. Adv Drug Deliv Rev. 2012;64:246-255. Available from: http://dx.doi.org/10.1016/j.addr.2012.09.022.

4. Doane TL, Burda C. The unique role of nanoparticles in nanomedicine: imaging, drug delivery and therapy. Chem Soc Rev. 2012;41(7): 2885-2911.

5. Dreaden EC, El-Sayed MA. Detecting and destroying cancer cells in more than one way with noble metals and different confinement properties on the nanoscale. Acc Chem Res. 2012;45(11):1854-1865.

6. Bedford EE, Spadavecchia J, Pradier CM, Gu FX. Surface plasmon resonance biosensors incorporating gold nanoparticles. Macromol Biosci. 2012;12(6):724-739.

7. An K, Somorjai GA. Size and shape control of metal nanoparticles for reaction selectivity in catalysis. Chem Cat Chem. 2012;4(10): 1512-1524

8. Baruah B, Craighead C, Abolarin C. One-phase synthesis of surface modified gold nanoparticles and generation of SERS substrate by seed growth method. Langmuir. 2012;28(43):15168-15176.

9. Lu AH, Salabas EL, Schüth F. Magnetic nanoparticles: synthesis, protection, functionalization, and application. Angew Chem Int Ed Engl. 2007;46(8):1222-1244.

10. Iravani S. Green synthesis of metal nanoparticles using plants. Green Chem. 2011;13(10):2638-2650.

11. Attard G, Casadesús M, Macaskie LE, Deplanche K. Biosynthesis of platinum nanoparticles by Escherichia coli MC4100: can such nanoparticles exhibit intrinsic surface enantioselectivity? Langmuir. 2012;28(11):5267-5274.

12. Ramanathan R, Field MR, O’Mullane AP, Smooker PM, Bhargava SK, Bansal V. Aqueous phase synthesis of copper nanoparticles: a link between heavy metal resistance and nanoparticle synthesis ability in bacterial systems. Nanoscale. 2013;5(6):2300-2306.

13. Dhillon GS, Brar SK, Kaur S, Verma M. Green approach for nanoparticle biosynthesis by fungi: current trends and applications. Crit Rev Biotechnol. 2012;32(1):49-73.

14. Asmathunisha N, Kathiresan K. A review on biosynthesis of nanoparticles by marine organisms. Colloids Surf B Biointerfaces. 2013;103:283-287.

15. Gan PP, Li SF. Potential of plant as a biological factory to synthesize gold and silver nanoparticles and their applications. Rev Environ Sci Biotechnol. 2012;11(2):169-206.

16. Ghosh S, Patil S, Ahire M, et al. Synthesis of silver nanoparticles using Dioscorea bulbifera tuber extract and evaluation of its synergistic potential in combination with antimicrobial agents. Int J Nanomedicine. 2012; 7:483-496.

17. Sujitha MV, Kannan S. Green synthesis of gold nanoparticles using Citrus fruits (Citrus limon, Citrus reticulata and Citrus sinensis) aqueous extract and its characterization. Spectrochim Acta A Mol Biomol Spectrosc. 2013;102:15-23.
18. Geethalakshmi R, Sarada DV. Gold and silver nanoparticles from Trianthema decandra: synthesis, characterization, and antimicrobial properties. Int J Nanomedicine. 2012;7:5375-5384.

19. Kouvaris P, Delimitis A, Zaspalis V, Papadopoulos D, Tsipas SA, Michailidis N. Green synthesis and characterization of silver nanoparticles produced using Arbutus unedo leaf extract. Mater Lett. 2012;76:18-20.

20. Chen X, Schluesener HJ. Nanosilver: a nanoproduct in medical application. Toxicol Lett. 2008;176(1):1-12.

21. Wong KK, Liu X. Silver nanoparticles - the real "silver bullet" in clinical medicine? Med Chem Comm. 2010;1:125-131

22. Lohse SE, Murphy CJ. Applications of colloidal inorganic nanoparticles: from medicine to energy. J Am Chem Soc. 2012;134(38): $15607-15620$

23. You C, Han C, Wang X, et al. The progress of silver nanoparticles in the antibacterial mechanism, clinical application and cytotoxicity. $\mathrm{Mol}$ Biol Rep. 2012;39(9):9193-9201.

24. Monteiro DR, Silva S, Negri M, et al. Silver nanoparticles: influence of stabilizing agent and diameter on antifungal activity against Candida albicans and Candida glabrata biofilms. Lett Appl Microbiol. 2012;54(5):383-391.

25. Krishnaraj C, Ramachandran R, Mohan K, Kalaichelvan PT. Optimization for rapid synthesis of silver nanoparticles and its effect on phytopathogenic fungi. Spectrochim Acta A Mol Biomol Spectrosc. 2012;93:95-99.

26. Martínez-Gutierrez F, Thi EP, Silverman JM, et al. Antibacterial activity, inflammatory response, coagulation and cytotoxicity effects of silver nanoparticles. Nanomedicine. 2012;8(3):328-336.

27. Park M, Im J, Shin M, et al. Highly stretchable electric circuits from a composite material of silver nanoparticles and elastomeric fibres. Nat Nanotechnol. 2012;7(12):803-809.

28. Akter T, Kim WS. Reversibly stretchable transparent conductive coatings of spray-deposited silver nanowires. ACS Appl Mater Interfaces. 2012;4(4):1855-1859

29. Gottesman R, Shukla S, Perkas N, Solovyov LA, Nitzan Y, Gedanken A. Sonochemical coating of paper by microbiocidal silver nanoparticles. Langmuir. 2011;27(2):720-726.

30. Osório I, Igreja R, Franco R, Cortez J. Incorporation of silver nanoparticles on textile materials by an aqueous procedure. Mater Lett. 2012;75:200-203.

31. MubarakAli D, Thajuddin N, Jeganathan K, Gunasekaran M. Plant extract mediated synthesis of silver and gold nanoparticles and its antibacterial activity against clinically isolated pathogens. Colloids Surf B Biointerfaces. 2011;85(2):360-365.

32. El-Nour KM, Efthaiha A, Al-Warthan A, Ammar RA. Synthesis and applications of silver nanoparticles. Arabian Journal of Chemistry. 2010;3(3):135-140

33. Gao M, Sun L, Wang Z, Zhao Y. Controlled synthesis of Ag nanoparticles with different morphologies and their antibacterial properties Mater Sci Eng C. 2013;33(1):397-404.

34. Njagi EC, Huang H, Stafford L, et al. Biosynthesis of iron and silver nanoparticles at room temperature using aqueous sorghum bran extracts. Langmuir. 2011;27(1):264-271.

35. Moulton MC, Braydich-Stolle LK, Nadagouda MN, Kunzelman S, Hussain SM, Varma RS. Synthesis, characterization and biocompatibility of "green" synthesized silver nanoparticles using tea polyphenols. Nanoscale. 2010;2(5):763-770.

36. Mallikarjuna K, Sushma NJ, Narasimha G, Manoj L, Raju BDP. Phytochemical fabrication and characterization of silver nanoparticles by using pepper leaf broth. Arabian Journal of Chemistry. 2013. In press.

37. Nadagouda MN, Varma RS. Green synthesis of silver and palladium nanoparticles at room temperature using coffee and tea extract. Green Chem. 2008;10:859-862.

38. Loo YY, Chieng BW, Nishibuchi M, Radu S. Synthesis of silver nanoparticles by using tea leaf extract from Camellia sinensis. Int $J$ Nanomedicine. 2012;7:4263-4267. 
39. Shameli K, Ahmad MB, Zamanian A, et al. Green biosynthesis of silver nanoparticles using Curcuma longa tuber powder. Int J Nanomedicine. 2012;7:5603-5610.

40. Roopan SM, Rohit, Madhumitha G, et al. Low-cost and eco-friendly phyto-synthesis of silver nanoparticles using Cocos nucifera coir extract and its larvicidal activity. Ind Crops Prod. 2013;43: 631-635.

41. Suman TY, Rajasree SRR, Kanchana A, Elizabeth SB. Biosynthesis, characterization and cytotoxic effect of plant mediated silver nanoparticles using Morinda citrifolia root extract. Colloids Surf B Biointerfaces. 2013;106:74-78.

42. Amin M, Anwar F, Janjua MR, Iqbal MA, Rashid U. Green synthesis of silver nanoparticles through reduction with solanum xanthocarpum L Berry extract: characterization, antimicrobial and urease inhibitory activities against Helicobacter pylori. Int J Mol Sci. 2012;13(8):9923-9941.

43. Edison TJ, Sethuraman MG. Instant green synthesis of silver nanoparticles using Terminalia chebula fruit extract and evaluation of their catalytic activity on reduction of methylene blue. Process Biochem. 2012;47(9):1351-1357.

44. Shameli K, Bin Ahmad M, Jaffar Al-Mulla EA, et al. Green biosynthesis of silver nanoparticles using Callicarpa maingayi stem bark extraction. Molecules. 2012;17(7):8506-8517.

45. Valli JS, Vaseeharam B. Biosynthesis of silver nanoparticles by Cissus quadrangularis extracts. Mater Lett. 2012;82:171-173. Available from: http://dx.doi.org/10.1016/j.matlet.2012.05.040.

46. Mohan Kumar K, Sinha M, Mandal BK, Ghosh AR, Siva Kumar K, Sreedhara Reddy P. Green synthesis of silver nanoparticles using Terminalia chebula extract at room temperature and their antimicrobial studies. Spectrochim Acta A Mol Biomol Spectrosc. 2012;91:228-233.
47. Khan M, Mousa AA, Syamasundar KV, Alkhathlan HZ. Determination of chemical constituents of leaf and stem essential oils of Artemisia monosperma from central Saudi Arabia. Nat Prod Commun. 2012;7:1079-1082.

48. Al-Otaibi MS, Al-Mayouf AM, Khan M, Mousa AA, Al-Mazroa SA, Alkhathlan HZ. Corrosion inhibitory action of some plant extracts on the corrosion of mild steel in acidic media. Arabian Journal of Chemistry. 2012. In press.

49. Williams CA, Harborne JB, Greenham JR, Grayer RJ, Kite GC, Eagles J. Variations in lipophilic and vacuolar flavonoids among European Pulicaria species. Phytochemistry. 2003;64(1):275-283.

50. Stavri M, Mathew KT, Gordon A, Shnyder SD, Falconer RA, Gibbons S. Guaianolide sesquiterpenes from Pulicaria crispa (Forssk.) Oliv. Phytochemistry. 2008;69(9):1915-1918.

51. Sathishkumar G, Gobinath C, Karpagam K, Hemamalini V, Premkumar K, Sivaramakrishnan S. Phyto-synthesis of silver nanoscale particles using Morinda citrifolia L. and its inhibitory activity against human pathogens. Colloids Surf B Biointerfaces. 2012;95:235-240.

52. Smitha SL, Nissamuddin KM, Philip D, Gopchandran KG. Studies on surface plasmon resonance and photoluminescence of silver nanoparticles. Spectrochim Acta A Mol Biomol Spectrosc. 2008; 71(1):186-190.

53. Philip D. Mangifera indica leaf-assisted biosynthesis of well-dispersed silver nanoparticles. Spectrochim Acta A Mol Biomol Spectrosc. 2011;78(1):327-331.

54. Kora AJ, Beedu SR, Jayaraman A. Size-controlled green synthesis of silver nanoparticles mediated by gum ghatti (Anogeissus latifolia) and its biological activity. Org Med Chem Lett. 2012;2(1):17-27.
International Journal of Nanomedicine

\section{Publish your work in this journal}

The International Journal of Nanomedicine is an international, peerreviewed journal focusing on the application of nanotechnology in diagnostics, therapeutics, and drug delivery systems throughout the biomedical field. This journal is indexed on PubMed Central, MedLine, CAS, SciSearch ${ }^{\circledR}$, Current Contents ${ }^{\circledR} /$ Clinical Medicine,

\section{Dovepress}

Journal Citation Reports/Science Edition, EMBase, Scopus and the Elsevier Bibliographic databases. The manuscript management system is completely online and includes a very quick and fair peer-review system, which is all easy to use. Visit http://www.dovepress.com/ testimonials.php to read real quotes from published authors. 